\title{
Resuscitation of the newborn
}

\author{
A D Milner
}

Despite even the most diligent care and monitoring, problems sometimes arise during labour that cause fetal asphyxia and lead either to death or to brain damage. As paediatricians, however, we cannot accept circumstances in which asphyxial damage occurs after delivery as a result of inadequate facilities, staffing levels, or training.

Since intubation and positive pressure ventilation were first recommended by Flagg in North America in 1928, ${ }^{1}$ and by Blaikley and Gibberd at Guy's Hospital in $1935,{ }^{2}$ a pattern of resuscitation had evolved based on extrapolation and assumption rather than on clinical measurement. There can be few areas of medicine in which the potential benefit is so great but which have been subjected to so little evaluation.

\section{Physiological measurements of lung expansion at birth}

In the absence of well controlled clinical trials, one logical approach is to assess how a healthy baby expands his lungs and starts regular spontaneous respiration. Karlberg et al reported data on the onset of breathing in 11 babies $^{3}$; of these, five generated inspiratory pressures of between 40 and $80 \mathrm{~cm} \mathrm{H}_{2} \mathrm{O}$ with a pattern suggesting that an initial pressure of at least $20 \mathrm{~cm} \mathrm{H} \mathrm{H}_{2} \mathrm{O}$ had to be exceeded before any air entered the lungs-the so called opening pressure. The remaining six, however, expanded their lungs at considerably lower pressures and without any opening pressure phenomenon. A similarly designed study in Nottingham showed a somewhat different pattern. ${ }^{4}$ The mean inspiratory pressure was only $22.7 \mathrm{~cm} \mathrm{H}_{2} \mathrm{O}$ and opening pressures greater than $10 \mathrm{~cm} \mathrm{H}_{2} \mathrm{O}$ were rarely seen. The inspiratory volume changes (mean 46 $\mathrm{ml}$ ) were similar to those previously reported by Karlberg et al, but 16 of the 17 babies established a reserve of air (functional residual capacity) by the end of the first breath, compared with only four of 11 in the Swedish study. ${ }^{3}$

One of the problems with both these studies was that a pressure measuring device had to be placed in the lower oesophagus and the face covered with a mask between the time the baby was born and the onset of the first breath, inevitably selecting babies who were slow to start breathing. This was particularly a feature in the study of Karlberg $e t a l$, in which the mean time to the first breath was over 30 seconds and on one occasion delayed until 93 seconds. ${ }^{3}$ To overcome this, data were collected on a further 24 babies in whom the device for measuring oesophageal pressure had been inserted after the baby's head had been delivered but while the trunk was still in the birth canal..$^{5}$ The volume changes were similar, with a mean inspiratory volume of $40.3 \mathrm{ml}$ and a mean functional residual capacity of $18.7 \mathrm{ml}$. The inspiratory pressures were a little higher (mean $33 \mathrm{~cm} \mathrm{H}_{2} \mathrm{O}$, range 6-103) but again an opening pressure was rarely seen, with air entering the lungs as soon as the intrathoracic pressure began to fall. In retrospect this is not surprising as the air/water interface immediately before the first breath is in the oropharynx rather than at the terminal bronchiolus.

The opening pressure phenomena described by Karlberg et al and seen in some of the Nottingham babies occurred because the water filled respiratory system has a relatively slow response time, compared with diaphragmatic contraction. This phase effect will be exaggerated in babies who are relatively asphyxiated and start to breathe with inspiratory gasping.

A further problem with all these studies is that pressures will be under-recorded if the measuring device is not situated in the lower third of the oesophagus. This is obviously difficult to achieve on all occasions in the delivery room. For this reason, further measurements were carried out using two micropressure transducers mounted on a single catheter, again passed through the baby's naries after the head had been delivered. ${ }^{6}$ Traces were only accepted if the distal transducer was obviously in the stomach and recording positive pressures during inspiration. This ensured that the proximal transducer was in the lower third of the oesophagus. In these studies the mean inspiratory pressure rose to $52 \mathrm{~cm} \mathrm{H}_{2} \mathrm{O}$ (range 28-105) and the median to $38.6 \mathrm{~cm} \mathrm{H} \mathrm{H}_{2} \mathrm{O}$; the inspiratory volume (mean $37.3 \mathrm{ml}$ ) and functional residual capacity $(15 \cdot 1 \mathrm{ml})$ remained largely unchanged. These indicated that previously recorded pressures of less than $20 \mathrm{~cm} \mathrm{H}_{2} \mathrm{O}$ were almost certainly artifactual. Meaurements have also been obtained on a small number of babies born by caesarean section-that is, not exposed to the squeezing effect of the birth canal. The inspiratory pressures and volumes were similar but only five of the 11 babies established a functional residual capacity with the first breath. ${ }^{7} \mathrm{~A}$ further factor that is important in aiding the clearance of lung fluid and the creation of a functional residual capacity is the prolonged high pressure that occurs during expiration and is produced by crying.

The pattern of breathing is also obviously important when planning a resuscitation protocol. In the first breath studies the inspiratory effort was maintained for 0.58 of a second
Department of Paediatric Respiratory Medicine, University of Nottingham, Professor Milner. 
(range $0 \cdot 20-1 \cdot 4$ ), and significant correlation was noted between the product of the inspiratory pressure and time, and the formation of a functional residual capacity. ${ }^{6}$

\section{Physiological measurements during resuscitation \\ INTUBATION}

These studies indicate that the resuscitation techniques currently recommended are significantly different from the pressure sequences found in the spontaneously breathing baby and may be less effective. This is borne out by what information we have on the efficacy of routine resuscitation at birth. Boon et al measured the volume changes associated with the use of an inflation pressure of $30 \mathrm{~cm} \mathrm{H} \mathrm{H}_{2} \mathrm{O}$ maintained for about one second in full term babies requiring resuscitation at birth. ${ }^{8}$ They found that this produced a mean volume change of only $15.3 \mathrm{ml}$ (range $0-62.5$ ) and in only three of the 20 was there a measurable volume of air in the lungs at the end of the first inflation, compared with 48 of 50 babies who started breathing spontaneously. ${ }^{9}$ In many babies the tidal exchange produced was actually less than the anatomical dead space and so was not producing effective ventilation. Analysis of the babies' response to the first few inflations showed that the most common response was for the baby to produce a high positive intrathoracic pressure ${ }^{10}$; this obviously impeded lung expansion. At other times the inflation pressure stimulated the baby to make inspiratory effort-the so called 'Heads' paradoxical reflex. This often led to remarkable improvement in the mechanical characteristics of the lung and the formation of an appreciable functional residual capacity. Inspection of the tidal volume trace showed that at the end of one second air was still entering the lungs - that is, the respiratory system was responding slowly to the inspiratory pressure. When this first inflation pressure was maintained for more than three seconds the mean inspiratory volume rose to $33.5 \mathrm{ml}$ (range 16.9-70) and the mean functional residual capacity to $15.9 \mathrm{ml}$ (range $11 \cdot 7-31 \cdot 0$ ), that is, figures similar to those achieved by babies who were breathing spontaneously. ${ }^{11}$ This prolonged inflation may also have compensated for the inevitable loss of the first cry.

In all these studies the inflation pressure was kept constant, so no allowance was made for differences in lung mechanics among babies. Further information on the most appropriate pressure was provided by Hull who used a volume limited system and attempted to inflate the lungs of babies who required resuscitation with a constant volume; he then measured both the resulting pressure and the rate at which a functional residual capacity was produced. ${ }^{12} \mathrm{He}$ found that although there were some who could be resuscitated satisfactorily with pressures of less than $30 \mathrm{~cm} \mathrm{H}_{2} \mathrm{O}$, others required pressures in excess of $40 \mathrm{~cm} \mathrm{H}_{2} \mathrm{O}$.

The generally recommended upper limit of $30 \mathrm{~cm} \mathrm{H}_{2} \mathrm{O}$ has been justified on the grounds that pressures in excess of this would be more likely to produce a pneumothorax. Our only information on this derives from a paper by Rosen and Laurence who subjected the isolated newborn lung to the increasing pressures until rupture occurred. ${ }^{13}$ This was a common occurrence once $60 \mathrm{~cm} \mathrm{H} \mathrm{H}_{2} \mathrm{O}$ had been exceeded, but rarely occurred when the pressure was below 35 $\mathbf{c m ~} \mathrm{H}_{2} \mathrm{O}$. This is, however, an artificial situation and analagous to identifying the maximum possible pressure for a car tyre by blowing up the isolated inner tube until it ruptures.

In many units throughout the world babies are resuscitated with anaesthetic rebreathing bags attached to the endotracheal tube by the criteria recommended by anaesthetists - that is, generating sufficient pressure to produce visible movement of the chest wall. This technique was used in a recent study on the resuscitation of 29 babies, and at the same time both the tidal exchange and inflation pressure were measured. ${ }^{14}$ The mean inflation pressure was

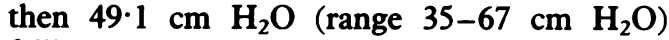
falling to $39 \mathrm{~cm} \mathrm{H}_{2} \mathrm{O}$ (range $28-57 \mathrm{~cm} \mathrm{H}_{2} \mathrm{O}$ ) at the end of the period of resuscitation. Interestingly, in the full term babies this produced tidal volumes of $40 \mathrm{ml}$ and often led to the formation of a functional residual capacity despite inspiratory times in the region of only half a second. As will be noticed, these figures are virtually identical to those achieved by babies who started breathing spontaneously.

\section{FACE MASK RESUSCITATION}

Bag and mask systems have been available for use in the labour ward for many years. These usually incorporate blow off valves, which are relatively crude in function and heavily dependent on the flow. Measurements made with five devices currently available showed that those with bag volumes of less than $300 \mathrm{ml}$ rarely produced ventilation greater than the anatomical dead space. ${ }^{15}$ When the bag was at least $500 \mathrm{ml}$ in volume, inflation volumes were closer to those achieved with conventional resuscitation. The main reason for this was that the larger bag allowed the inflation pressure to be maintained for longer. Even with these, however, it is likely that the apparent success achieved with these devices in the labour suite results largely from the induction of a Heads paradoxical reflex, rather than by achieving adequate ventilation alone. An alternative approach has been to attach a $T$ piece to a soft, ring shaped face mask, to incorporate a blow off system in the inspiratory line, and to occlude the $\mathrm{T}$ piece intermittently with a finger. ${ }^{16}$ This is a much easier device to use, it can be applied with one hand leaving the other one free either to steady the head or to hold the stethoscope bell to the chest, and it produces appreciably better tidal exchange as it allows inflation pressure to be maintained for at least a second. Current experience in Nottingham indicates that the routine use of this device can reduce the need for intubation by up to half. Although this was considered to be an innovation, the device was first described in the American fournal of Medicine in 1926 and then seemed to have disappeared from use for nearly 60 years. ${ }^{17}$

As stated earlier, though these measurements 
give us information on the relative efficacy of the different methods and patterns of resuscitation, what is totally lacking is any controlled trial comparing long term outcomes. Such a study would be extremely difficult to carry out, and would have to be large; failing this it seems reasonable to use the information available when drawing up a resuscitation protocol.

MANAGEMENT AT BIRTH AND INDICATION FOR RESUSCITATION

Although the Apgar score may be of some epidemiological interest it is of little help in determining which babies will require resuscitation, and of limited value in determining either short term or long term outcome. ${ }^{18}$ It is obviously essential to reduce heat loss by wiping excess water off the baby during the first few seconds, ensuring that the baby is in a relatively warm environment, and that there are no gross congenital abnormalities that might deter one from proceeding to resuscitation. Providing that the baby's heart rate is in excess of $80 /$ minute, it is acceptable to delay intervention for up to a minute even if there are no respiratory efforts whatsoever. Nasopharyngeal and oropharyngeal suction are sometimes carried out on the assumption that this will stimulate the baby to breathe. There is, however, good evidence that overenthusiastic pharyngeal suction can actually delay the onset of respiration, and this manoeuvre is probably not indicated unless the upper airway is contaminated with blood or meconium. It remains entirely acceptable to stimulate the baby gently-for example, by flicking a foot. If by 1 minute of age the baby is still making inadequate respiratory efforts, mask and $T$ piece resuscitation should be started, and an inspiratory pressure of 20 to $30 \mathrm{~cm} \mathrm{H}_{2} \mathrm{O}$ should be maintained for at least a second initially. ${ }^{16}$ If this device is not available, a bag and mask system will often be successful, particularly if the inflation bag has a volume of at least $500 \mathrm{ml}$.

If this form of resuscitation fails to achieve adequate air entry, or if the baby's heart rate falls to less than $80 /$ minute at any time after delivery, intubation will be required, Again, maintaining the first inflation for two to three seconds will lead to a more rapid resolution of hypoxia. Start with inflation pressures of 20 to $30 \mathrm{~cm} \mathrm{H} \mathrm{H}_{2} \mathrm{O}$, but it may be necessary to raise this to 40 or even 50 if air entry is poor-particularly if there has been oligohydramnios or the infant has a diaphragmatic hernia that has been diagnosed antenatally-both conditions that are associated with pulmonary hypoplasia. ${ }^{19}$

There seems little reason not to use $100 \%$ oxygen in the resuscitation of full term babies. There was a theoretical worry that absorption atalectasis might occur more often if this was done, particularly if the baby tended to hypoventilate after extubation. There is no evidence to show that this does occur, however, and indeed breathing $100 \%$ oxygen for up to 15 minutes in the first hours of birth has no measurable effect on lung volume, ${ }^{20}$ probably because microbubbles are formed, which persist in the lung until lung fluid absorption has occurred. $^{21}$

\section{EXTERNAL CARDIAC MASSAGE}

If peripheral pulses are absent and the apex beat is either imperceptible or less than 60 /minute, external cardiac massage should be started. There is now little doubt that the 'hands round the chest method'-that is placing the tips of the fingers along the spine and compressing the lower sternum with both thumbs, produces better cardiac output than compressing the sternum with the index and middle fingers alone. ${ }^{22}$ The aim should be to produce three chest compressions for every lung inflation. Sometimes this is sufficient to lead to an obvious improvement. For the remainder it will be necessary to start treatment with drugs.

\section{DRUGS IN RESUSCITATION}

By this stage the babies have inevitably developed severe metabolic acidosis, almost certainly with a $\mathrm{pH}$ of less than $6 \cdot 8$. Although adrenaline is more likely to work after this acidosis has been at least partly relieved, if it is given directly down the endotracheal tube $(0.5 \mathrm{ml}$ $1 / 10000$ ), it does sometimes have an immediate effect. $^{23}$ It is reasonable to try this while arrangements are made to give $4 \cdot 2 \%$ sodium bicarbonate ( $20 \mathrm{ml}$ to a large baby) either through an umbilical venous catheter or by direct injection into the vein within the cord. Once this has been given, further doses of adrenaline can be given either directly into the umbilical vein or again down the endotracheal tube. This response to endotracheal adrenaline is surprising in view of the fact that the pulmonary circulation is extremely small before the onset of spontaneous ventilation. Babies who fail to respond to adrenaline and external cardiac massage are sometimes given calcium gluconate, although evidence that this is useful is lacking.

When resuscitation has led to good chest wall movement, symmetrical air entry, and improvements in cardiac output and appearance but respiration fails to start, respiratory depression from opiates given to the mother should be considered. It is then appropriate to give intravenous naloxone $20-40 \mu \mathrm{g}$. If this produces a response it is recommended that an additional $200 \mu \mathrm{g}$ should be given intramuscularly to produce a more prolonged effect.

\section{WHEN TO STOP}

There have now been a number of studies that showed that babies who take up to 20 minutes to respond, even after the most intensive resuscitation, can subsequently develop entirely normally. ${ }^{24-26}$ Such an outcome is rarely seen, however, in babies who have failed to produce even intermittent respiratory efforts by 30 minutes. For this reason many units have now adopted a policy of withdrawing treatment at 20 to $\mathbf{3 0}$ minutes from those who fail to show any sign of life other than an effective cardiac output, but if necessary they provide supportive 
ventilation for the next 24 to 48 hours. A proportion of these babies will inevitably die from severe asphyxial encephalopathy. There is currently some dispute about the number of these babies who will subsequently be entirely normal, and estimates range from 30 to $85 \%{ }^{27}$

\section{RESUSCITATION OF PRETERM BABIES}

Most babies of over 32 to 34 weeks' gestation will start to breathe spontaneously without any problems. The more immature the baby, the more likely it is that intervention will be required. Some units will electively intubate and ventilate all babies of less than 28 or even 30 weeks' gestation at birth on the grounds that this will ensure that the baby's lungs are expanded rapidly and reduce the incidence of subsequent respiratory distress. This policy is often adopted if the distance between the labour suite and the neonatal unit is substantial and there are worries that the baby may deteriorate during transport. There is one published study that shows that when a policy of elective intubation is compared with rigid intubation criteria-that is, only $3 \%$ of babies of less than 30 weeks' gestation-elective resuscitation was associated with a reduction in mortality from 70 to $50 \% .{ }^{28} \mathrm{~A}$ further smaller study (DJ Field, AD Milner, unpublished observations), in which an intermediate policy was adopted-that is babies not breathing regularly by 30 seconds were given bag and mask resuscitation, and those not breathing regularly by 1 minute were intubated-produced results that were identical to elective intubation for all babies. This is the policy that we have adopted in Nottingham, where we intubate between 60 and $70 \%$ of all babies of less than 30 weeks' gestation.

There are some centres that regularly use $40 \%$ oxygen for resuscitating preterm babies on the grounds that high oxygen exposure even for a short time might increase the incidence of retrolental fibroplasia. It is, however, extremely unlikely that exposure to $100 \%$ oxygen for even 15 to 20 minutes is likely to have any long term adverse effects. There has also been some dispute about the inflation pressures that should be used for preterm babies. It is recognised that preterm babies are more prone both to pneumothoraces and to pulmonary interstitial emphysema. These are less likely to occur if low inflation pressures are used. Preterm babies are likely to be deficient in surfactant, however, and so may need relatively high inflation pressures to achieve adequate tidal exchange and form a functional residual capacity. What information is available suggests that endotracheal resuscitation of preterm babies with $30 \mathrm{~cm} \mathrm{H}_{2} \mathrm{O}$ pressure is less likely to produce adequate alveolar ventilation than in full term asphyxiated babies. ${ }^{29}$ On the other hand, the study in which babies were ventilated with an anaesthetic rebreathing bag showed no tendency for higher pressures to be required as gestational age fell, but there was a significant relationship between failure to form a functional residual capacity and the development of respiratory distress syndrome and subsequent death. ${ }^{14}$ On balance, it seems reasonable to start with a pressure of 20 to $25 \mathrm{~cm} \mathrm{H} \mathrm{H}_{2} \mathrm{O}$ but to raise this if resuscitation fails to produce chest wall movement and satisfactory breath sounds.

There remains the problem of babies whose gestational age is less than 26 weeks. In some units the policy is to intubate babies even if the gestational age is as young as 23 or 22 weeks, and then proceed if necessary with supportive ventilation until the outcome is obvious. Other units practise more measured responses, only proceeding to intubation in those babies who make some respiratory efforts and are obviously of at least 23 to 24 weeks' gestation. I am more in sympathy with the latter than the former. Further studies are obviously needed to resolve this difficult ethical dilemma.

1 Flagg PJ. The treatment of asphyxia in the newborn. $\mathcal{F} A M A$ 1928:91:788-91.

2 Blaikley LB, Gibberd GF. Asphyxia neonatorum. Lance

3 Karlberg P, Cherry RB, Escardo FE, Koch G. Pulmonary ventilation and mechanics of breathing in the first minute of life, including the onset of respiration. Acta Paediat Scand 1962;51:121-36.

4 Milner AD, Saunders RA. Pressure and volume changes during the first breath of human neonates. Arch Dis Child 1977;52:918-24.

5 Saunders RA, Milner AD. Pulmonary pressure/volume relatonships during the last phase of delivery and the first postnatal breaths in the human subject. $\mathcal{F}$ Pediatr 1978;93:667.

6 Vyas H, Field D, Milner AD, Hopkin IE. Determinants of the first inspiratory volume and functional residual capacity at birth. Pediatr Pulmonol 1986;2:189-93.

7 Vyas H, Milner AD, Hopkin IE. Comparison of intrathoracic pressure and volume changes during the spontaneous onset pressure and volume changes during the spontaneous onset
of respiration in babies born by caesarean section and by of respiration in babies born by caesarean secti
vaginal delivery. $\mathcal{f}$ Pediatr 1981;99:787-91.

8 Boon AW, Milner AD, Hopkin IE. Lung expansion, tidal volume and formation of functional residual capacity during resuscitation of asphyxiated neonates. $\mathcal{J}$ Pediatr ing resuscitatio

9 Vyas H, Milner AD, Hopkin IE. Intrathoracic pressure and volume changes during onset of respiration. $\mathcal{f}$ Pediat 1981;99:787-91

10 Boon AW, Milner AD, Hopkin IE. Physiological responses of the newborn to resuscitation. Arch Dis Child $1979 ; 54: 492-8$.

11 Vyas H, Milner AD, Hopkin IE, Boon AW. Physiological responses to prolonged and slow rise inflation. $\mathcal{F}$ Pediat 1981;99:635-9.

12 Hull D. Lung expansion and ventilation during resuscitation of asphyxiated newborn infants. $\mathcal{F}$ Pediatr 1969;75:47-58.

13 Rosen M, Laurence KM. Expansion pressure and rupture pressures in the newborn lung. Lancet 1965;ii:721-2

14 Upton C, Milner AD. Endotracheal resuscitation of 21-2. using a rebreathing bag. Arch Dis Child 1991;66:39-42.

15 Field DJ, Milner AD, Hopkin IE. Efficiency of manual resuscitators at birth. Arch Dis Child 1986;61:300-2.

16 Hoskyns EW, Milner AD, Hopkin IE. A simple method of face mask resuscitation at birth. Arch Dis Child face mask res

17 Henderson $\mathrm{Y}$. The prevention and treatment of asphyxia in the newborn. $7 A M A$ 1928;90:583-6.

18 Anonymous. Is the Apgar score outmoded? [Editorial]. Lancet 1989; : Is the

19 Blott M, Greenough A, Nicolaides KH. Fetal breathing movements in pregnancies complicated by premature membrane rupture in the second trimester. Early Hum Dev 1990;21:41-8.

20 Boon AW, Ward-McQuaid JMC, Milner AD, Hopkin IE. Thoracic gas volume, helium functional residual capacity and air trapping in the first six hours of life: the effects of
oxygen administration. Early Hum Dev 1981;5:157-66.

21 Scarpelli EM. Intrapulmonary foam at birth-an adaptional phenomenon. Pediatr Res 1978;12:1070-6.

22 David R. Closed chest cardiac massage in the newborn infant. Pediatrics 1988;81:552-4.

23 Greenberg MI, Roberts JR, Baskin SI. Use of endotracheally administered epinephrine on a pediatric patient. $A m \mathcal{F} D$ is administered epinephrine

24 Scott H. Outcome of very severe birth asphyxia. Arch Dis Child 1976;51:712-6.

25 Ergander U, Eriksson $M$, Zetterstrom R. Severe birth asphyxia: incidence and prediction of outcome in the Stockholm xia: incidence and prediction of outcome in
area. Acta Paediatr Scand 1983;72:321-5.

26 Koppe JG, Kleinerd AG. Severe asphyxia and outcome of Koppe JG, Kleinerd AG. Severe asphyxia and

27 Levine MI, Sands C, Grindulis H. Moore JR. Comparison of two methods of predicting outcome in perinatal asphyxia. Lancet 1986;i:67-71.

28 Drew J. Immediate intubation at birth of very low birth weight infants: effect on survival. Am $\boldsymbol{F}$ Dis Child $1982 ; 136: 207-10$

29 Hoskyns EW, Boon AW, Vyas H, Milner AD, Hopkin IE. Endotracheal resuscitation of preterm infants at birth. Arch Dis Child 1987;62:663-7. 